\title{
Ocorrência de Pythiella vernalis em Pythium aphanidermatum de cultura hidropônica de agrião no Brasil
}

\author{
Carmen Lidia Amorim Pires-Zottarelli ${ }^{1}$, Amaury da Silva dos Santos ${ }^{2}$, Adauto Ivo Milanez ${ }^{1} \&$ Matheus Aparecido \\ Pereira Cipriano ${ }^{3}$
}

\begin{abstract}
${ }^{1}$ Instituto de Botânica de São Paulo, Seção de Micologia e Liquenologia, CP 3005, 01061-970 São Paulo/SP, Brasil, ${ }^{2}$ Embrapa Tabuleiros Costeiros, Av. Beira Mar, 3250, 49025-040 Aracajú/SE, ${ }^{3}$ Instituto Agronômico, CP 28, 13020-902 Campinas/SP.

Autor para correspondência: Carmen Lidia Amorim Pires Zottarelli.

Data de chegada: 10/07/2007. Aceito para publicação em: 14/07/2009.
\end{abstract}

1499

\section{RESUMO}

Pires-Zottarelli, C.L.A.; Santos, A.S.; Milanez, A.I.; Cipriano, M.A.P. Ocorrência de Pythiella vernalis em Pythium aphanidermatum de cultura hidropônica de agrião no Brasil. Summa Phytopathologica, v.35, n.4, p.325-326, 2009

Pythiella vernalis foi isolada de Pythium aphanidermatum de cultura hidropônica de agrião, no município de Taubaté, SP, Brasil. É a primeira citação de Pythiella vernalis no Brasil e a primeira referência mundial da espécie em Pythium aphanidermatum.

Palavras-chave adicionais: hiperparasita, Lepidium sativum, Oomycota

\section{ABSTRACT}

Pires-Zottarelli, C. L. A.; Santos, A. da S. dos; Milanez, A. I. Occurrence of Pythiella vernalis from Pythium aphanidermatum on hydroponic culture of Lepidium sativum in Brazil. Summa Phytopathologica, v.35, n.4, p.325-326, 2009

Pythiella vernalis have been isolated from Pythium aphanidermatum on hydroponic culture of Lepidium sativum, in the municipality of Taubaté, São
Paulo State, Brazil. It is the first report of the Pythiella vernalis in Brazil and the first world reference of the occurrence of this species in P. aphanidermatum.

Keywords: hiperparasite, Lepidium sativum, Oomycota.

Pythiella é um gênero pertencente a Lagenaceae, família criada por Dick (4) e considerada por ele como "incertae sedis" dentro do Reino Straminipila. Possui apenas duas espécies validamente publicadas, Pythiella pythii (Whiffen) M. W. Dick e P. vernalis (4). Pythiella vernalis Couch, espécie tipo do gênero, originária da América do Norte, caracteriza-se como um hiperparasita endobiótico holocárpico de Pythium (7, 4), tendo sido descrita por Couch (2) como parasita de Pythium gracile Schenk (= P. diclinum Tokunaga) e $P$. dictyosporum Racib. (= Cystosiphon dictyosporum (Racib.) M.W. Dick, ambos parasitas em Spirogyra areolata Lagerh. e Spirogyra sp.

O objetivo inicial da pesquisa foi identificar o patógeno procedente de cultura hidropônica de agrião (Lepidium sativum L.), o qual foi isolado de raízes sintomáticas, em fevereiro de 2006, provenientes da cidade de Taubaté (SP). O isolamento do patógeno foi realizado a partir da lavagem, em água esterilizada, das raízes necróticas, subseqüente lavagem em solução de hipoclorito de sódio a 1,5\%, secagem em papel filtro, e posterior transferência de fragmentos radiculares para meio de cultura BDA (Batata-Dextrose-Ágar). Após purificação, o isolado crescido foi transferido para placa de Petri esterilizada, a qual foram adicionadas água destilada esterilizada e duas metades de sementes, previamente fervidas, de Sorghum sp. A identificação do espécime de Pythium foi realizada segundo PlaatsNiterink (8).

Concomitantemente à identificação do patógeno como Pythium aphanidermatum (Edson) Fitzp., espécie comum em cultivos hidropônicos $(10,5,1)$, constatou-se a presença de um hiperparasita, identificado como Pythiella vernalis por meio de literatura específica $(9,7,4)$. O espécime de talo endobiótico, holocárpico, em $P$. aphanidermatum (Figura 1A), apresentou zoosporângios globosos, $12-24 \mu \mathrm{m}$ diâm., solitários ou até 10 em uma única dilatação (Figuras 1B, 1C); liberação dos zoósporos biflagelados por meio de um único tubo de descarga, de comprimento variável (Figura 1C). Oogônios esféricos, 15 -21(-24) $\mu \mathrm{m}$ diâm., com um único oósporo subcêntrico, esférico, 13 - 16,5 $\mu \mathrm{m}$ diâm., parede espessada e normalmente rodeada por uma pequena quantidade de periplasma. Anterídio esférico, freqüentemente achatado, $9-10 \times 5,5-6 \mu \mathrm{m}$ (Figuras 1D, 1E); tubo de fertilização delicado persistente (Figura 1F).

As características apresentadas pelo espécime concordam com a literatura existente, com exceção do número de zoosporângios por dilatação (1 a 4), tendo sido observado neste estudo até 10 por dilatação. Foi também observado apenas um único tubo de descarga, quando a literatura indica de 1 a $5(7,9)$.

Tentativas de infecção foram realizadas em outros isolados de $P$. aphanidermatum, não tendo sido obtido sucesso.

Pythiella vernalis é espécie mundialmente rara. Após descrição original, foi somente mencionada por Karling (6) como hiperparasita de Pythium sp., parasita de Vaucheria germinata (Vaucher) de Candolle in Lamarck \& de Candolle, em um lago nos Estados Unidos e, da Polônia, por Czeczuga (3), como parasita de Pythium sp. em amostra de água.

Este é o primeiro relato de $P$. vernalis no Brasil, e a primeira referência mundial da espécie em $P$. aphanidermatum. 

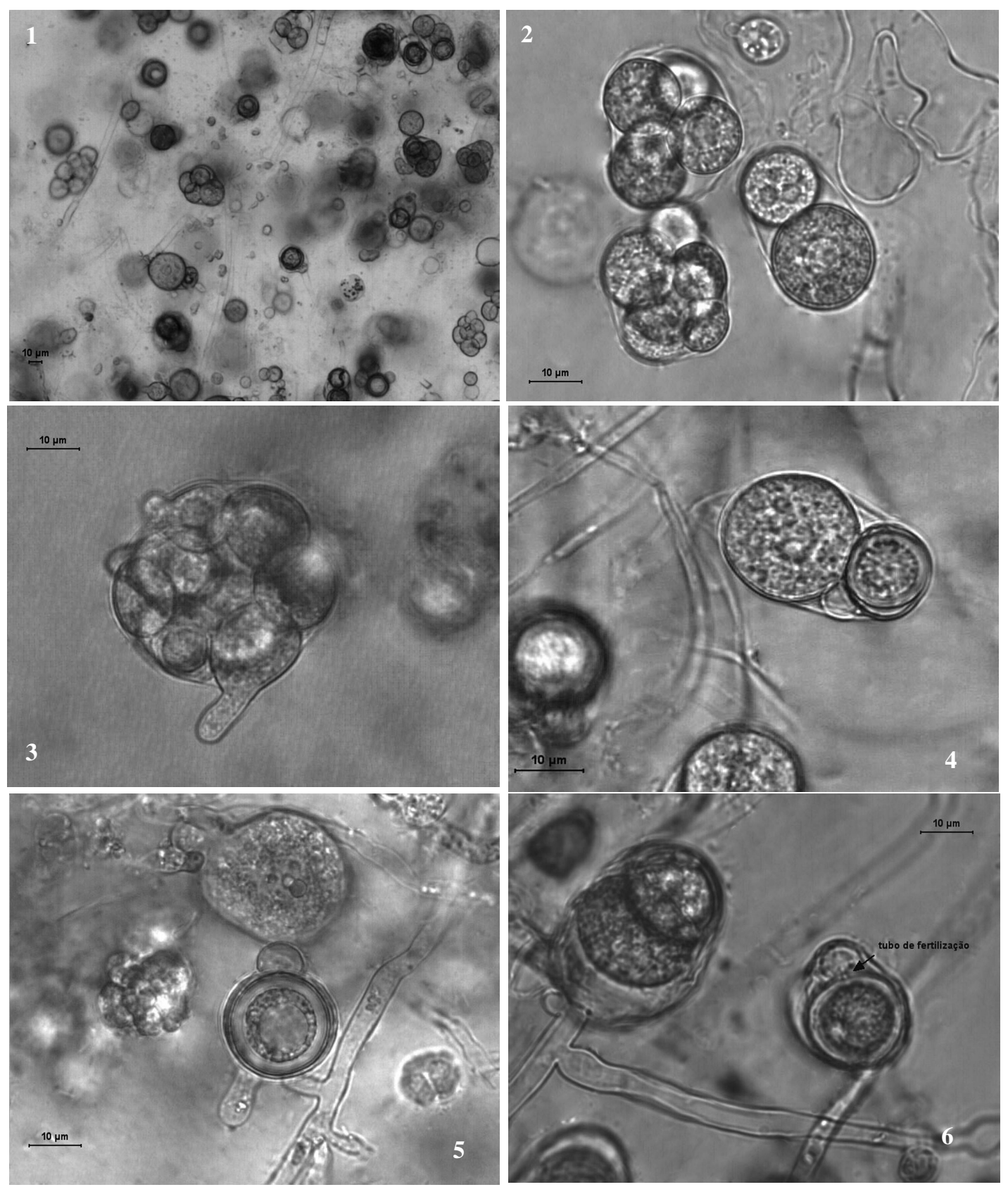

Figura 1. Pythiella vernalis. (A) aspecto geral da infecção em Pythium aphanidermatum; (B) zoosporângios dentro de zoosporângio de P. aphanidermatum; (C) Zoosporângios dentro de uma única dilatação; (D) Zoosporângio, oogônio com oósporo e anterídio dentro de uma dilatação; (E) Oogônio com oósporo subcêntrico e anterídio dentro de uma dilatação; (F) Detalhe do tubo de fertilização.

\section{REFERÊNCIAS BIBLIOGRÁFICAS}

1. Corrêa, E. B. Controle de podridão radicular (Pythium aphanidermatum) e promoção de crescimento em alface hidropônica. 2006. 96 f. Dissertação (Mestrado em Agronomia) Universidade Federal de Lavras, Lavras.

2. Couch, J. N. New or little Chytridiales. Mycologia, New York, v. 27, n. 2, p.160-175, 1935

3. Czeczuga, B. Studies of aquatic fungi. XVIII. Aquatic fungi in lake Sniardwy and eighteen neighbouring lakes. Internationale Revue der Gesamten Hydrobiologie, Berlin, v. 76, n. 1, p. 121$135,1991$.

4. Dick, M. W. Straminipilous fungi: systematics of the peronosporomycetes, including accounts of the marine straminipilous protists, the plasmodiophorids and similar organisms. Dordrecht: Kluwer, 2001. 670p.
5. Herrero, M. L.; Hermansen, A.; Elen O. N. Occurrence of Pythium spp. and Phytophthora spp. in Norwegian greenhouses and their pathogenicity on cucumber seedlings. Journal of Phytopathology, Berlim, v. 15, p.36-41, 2003.

6. Karling, J. S. A new Olpidiopsis parasite of Karlingia rosea from Maryland. Mycologia, New York, v. 41, p. 240-276, 1949.

7. Karling, J. S. Predominantly holocarpic and eucarpic simple biflagellate phycomycetes. $2^{\text {nd }}$ ed. Vaduz: J. Cramer, 1981. $252 \mathrm{p}$.

8. Plaats-Niterink, A. J. van der. Monograph of genus Pythium. Studies in Mycology, Baarn, v. 21, p.1-242, 1981.

9. Sparrow, F. K., Jr. Aquatic phycomycetes. University of Michigan Press. $2^{\text {nd }}$ ed. Ann Arbor: University of Michigan Press, 1960. $1187 \mathrm{p}$.

10. Stanghellini, M. E.; Rasmussen, S. L. Hydroponics - a solution for zoosporic pathogens. Plant Disease, St. Paul, v. 78, p.1129-11 